Piwulang 8 (1)(2020)
Teaching
http://journal.unnes.ac.id/sju/index.php/piwulang

\title{
PENGEMBANGAN MULTIMEDIA INTERAKTIF PEMBELAJARAN MEMBACA TEKS BERHURUF JAWA UNTUK SISWA KELAS VII SMP DI KECAMATAN UNGARAN TIMUR
}

\author{
Fajar Arum Sari ${ }^{1}$, Esti Sudi Utami², Endang Kurniati ${ }^{3}$ \\ 1,2,3 Jurusan Bahasa Jawa, Fakultas Bahasa dan Seni, Universitas Negeri Semarang, Indonesia \\ Corresponding Author: fajararum60@gmail.com ${ }^{1}$
}

\begin{abstract}
Abstrak
Siswa Kelas VII SMP di Kecamatan Ungaran Timur merasa bosan dengan pembelajaran membaca teks berhuruf Jawa yang monoton. Hal ini dikarenakan guru hanya menggunakan buku ajar, sehingga minat siswa dalam membaca teks berhuruf Jawa kurang. Oleh karena itu, tujuan penelitian ini untuk mengembangkan multimedia interaktif pembelajaran membaca teks berhuruf Jawa. Metode yang digunakan dalam penelitian ini yaitu research and developmen (R and D). Hasil penelitian ini berupa prototipe multimedia interaktif pembelajaran membaca teks berhuruf Jawa. Prototipe disusun berdasarkan kebutuhan siswa dan guru. Bentuk prototipe berupa aplikasi multimedia interaktif. Penayangan teks berhuruf Jawa melalui cerita bergambar dan disertai audio sebagai konfirmasi. Desain produk tersebut diuji validasi oleh ahli medi, ahli materi, dan guru sebagai pengguna. Setelah dilakukan perbaikan desain produk sesuai dengan saran validator, multimedia interaktif pembelajaran membaca teks berhuruf Jawa dianggap layak untuk digunakan oleh siswa kelas VII SMP di Kecamatan Ungaran Timur.
\end{abstract}

Kata Kunci: multimedia interaktif; membaca; teks berhuruf Jawa

\begin{abstract}
Grade VII junior high in Ungaran Timur was bored with learning to read text in a monotonous Java. This is due to gurus only use the textbook, so that interest students in reading the text in Java is less. Therefore, the purpose of this research is to develop interactive multimedia learning reading text in Java. The methods used in this research, namely research and development ( $R$ and $D$ ). The results of this research in the form of a prototype interactive multimedia learning reading text in Java. The prototype drawn up based on the needs of students and teachers. The shape of the prototype in the form of interactive multimedia applications. Lettered text impressions of Java through a picture story and an accompanying audio as a confirmation. The tested product design validation by expert medi, material, and teachers as users. After the repair of the product design in accordance with the suggestions of the validator, interactive multimedia learning reading text in Java considered worthy to be used by students of Class VII junior high in Ungaran Timur.
\end{abstract}

Keywords: interactive multimedia, reading, Javanese text

(C) 2020 Universitas Negeri Semarang

p-ISSN 2252-6307

e-ISSN 2714-867X 
Fajar Arum Sari, dkk/ Piwulang 8 (1) (2020)

\section{PENDAHULUAN}

Secara geografis, bahasa Jawa merupakan bahasa yang dipakai di daerah-daerah Provinsi Jawa Tengah, DIY, dan Jawa Timur (Setiyadi dalam Mulyana, 2008). Pada kurikulum muatan lokal bahasa Jawa, terdapat kompetensi dasar yang harus dikuasai siswa kelas VII sekolah menengah pertama, yaitu membaca nyaring teks berhuruf Jawa dengan penerapan sandhangan dan pasangan. Kompetensi ini nantinya akan mempermudah siswa untuk mencapai kompetensi selanjutnya yaitu menulis teks berhuruf Jawa dengan penerapan sandhangan dan pasangan. Namun setelah dilakukan wawancara mengenai penguasaan siswa kelas VII SMP terhadap materi membaca teks berhuruf Jawa, ditemukan fakta bahwa siswa merasa bosan pada pembelajaran membaca teks berhuruf Jawa. Hal ini dikarenaka kurangnya media pembelajaran membaca teks berhuruf Jawa yang menarik, atraktif, dan interaktif.

Padahal, media pembelajaran memiliki manfaat untuk menarik perhatian siswa sehingga akan menumbuhkan motivasi belajar dan membuat siswa lebih aktif dalam pembelajaran. Selain itu materi pembelajaran akan lebih mudah dipahami oleh siswa dan metode mengajar menjadi lebih variatif sehingga dapat mengurangi kebosanan belajar (Sudjana \& Riva'i dalam Arsyad, 2008: 24-25). Proses pembelajaran juga dapat berlangsung secara optimal dengan adanya media pembelajaran karena media berfungsi untuk membantu penyampaian pesan atau informasi dari guru kepada siswa ataupun sebaliknya (Arda dkk, 2015: 69). Kegunaan lain dari media dalam proses belajar mengajar yaitu untuk memperjelas penyajian pesan, mengatasi sikap pasif siswa agar lebih semangat dan mandiri dalam belajar, mengatasi keterbatasan ruang, waktu, dan daya indera (Sadiman dkk, 2002: 16).

Penelitian ini merealisasikan kebutuhan siswa akan media pembelajaran yang menarik, atraktif, dan interaktif dengan dikembangkannya sebuah produk multimedia interaktif pembelajaran membaca teks berhuruf Jawa. Multimedia merupakan gabungan dari elemenelemen yang saling berkaitan dan terdiri dari kombinasi teks, grafik, seni, suara, animasi, dan video. Dikatakan sebagai multimedia interaktif ketika media tersebut dapat mengikuti keinginan pengguna seperti menampilkan proyek dan mengontrol apa dan kapan elemen diserahkan (Vaughan dalam Munir, 2013:111). Sejalan dengan pendapat tersebut, multimedia interaktif juga mampu melatih keterampilan siswa dalam membaca teks berhuruf Jawa secara mandiri. Terdapat audio yang berguna sebagai konfirmasi cara membaca yang benar, sehingga siswa tetap dapat mengasah keterampilan membaca teks berhuruf Jawa kapanpun dan dimanapun. Penggunaan multimedia juga dapat mengasah kemampuan siswa berprestasi, mengubah siswa pasif menjadi aktif, guru hanya sebagai mentor, dan siswa sebagai kegiatan pembelajaran (Riyanto dan Gunarhadi, 2017: 56-57).

Adapun tujuan yang hendak dicapai dari penelitian ini yaitu: 1) Mendeskripsikan kebutuhan siswa dan guru terhadap media pembelajaran membaca teks berhuruf Jawa untuk siswa kelas VII SMP. 2) Menyusun 
Fajar Arum Sari, dkk/ Piwulang 8 (1) (2020)

prototipe media interaktif pembelajaran membaca teks berhuruf Jawa untuk siswa kelas VII SMP. 3) Memaparkan hasil validasi ahli terhadap prototipe media interaktif pembelajaran membaca teks berhuruf Jawa untuk siswa kelas VII SMP.

\section{METODE PENELITIAN}

Penelitian ini menggunakan metode Research and Development (R\&D). Metode tersebut bertujuan untuk mengembangkan sebuah produk baru ataupun menyempurnakan produk yang sudah ada (Sukmadinata, 2013: 164).

Langkah-langkah pelaksanaan pada penelitian ini merujuk pada pemaparan yang dikemukakan oleh Sugiyono (2010: 409) yaitu (1) potensi dan masalah, (2) pengumpulan data, (3) desain produk, (4) validasi desain, (5) revisi desain, (6) ujicoba produk, (7) revisi produk, (8) ujicoba pemakaian, (9) revisi produk, (10) produksi masal. Setelah disesuaikan dengan tujuan penelitian ini yaitu untuk menyusun prototype media interaktif pembelajaran membaca teks berhuruf Jawa, langkah-langkah tersebut dibatasi menjadi lima langkah penelitian saja yaitu (1) potensi dan masalah, (2) pengumpulan data, (3) desain produk, (4) validasi desain, (5) revisi desain.

Subjek penelitian ini yaitu 3 guru bahasa Jawa dan 93 siswa kelas VII SMP di Kecamatan Ungaran Timur, serta ahli materi dan ahli media. Data penelitian ini diperoleh melalui wawancara, observasi, dan angket. Teknik analisis data yang digunakan pada penelitian ini yaitu analisis deskriptif kualitatif, yaitu teknik analisis melalui pemaparan data dan simpulan data.

\section{HASIL DAN PEMBAHASAN}

\section{Kebutuhan Siswa dan Guru terhadap Multimedia Interaktif}

Siswa dan guru kelas VII SMP di Kecamatan Ungaran Timur membutuhkan adanya multimedia interaktif pembelajaran membaca teks berhuruf Jawa. Materi yang dibutuhkan yaitu cerita Rawa Pening dengan alasan cerita tersebut sudah akrab di telinga siswa, sehingga lebih mudah untuk dipahami. Gambar ilustrasi yang dibutuhkan yaitu cerita bergambar dengan alasan agar teks lebih mudah dibaca. Guru membutuhkan dialek Semarang dengan alasan dialek tersebut sesuai dengan daerah tempat tinggal siswa. Dialek Semarang juga sesuai apabila digunakan pada cerita rakyat Rawa Pening yang berasal dari Kabupaten Semarang. Selain dialek, guru juga membutuhkan bahasa Jawa ragam krama untuk digunakan pada multimedia interaktif dengan alasan agar siswa terampil dalam berbicara krama dengan orang yang lebih tua. Oleh karena itu, multimedia interaktif pembelajaran membaca teks berhuruf Jawa menggunakan materi cerita rakyat "Dumadine Rawa Pening" yang disertai dengan ilustrasi cerita bergambar dan menggunakan ragam bahasa krama dialek Semarang.

Mengenai bentuk fisik multimedia interaktif, guru membutuhkan jenis huruf Tuladha Jejeg dengan alasan guru dan siswa sudah terbiasa menggunakan jenis huruf tersebut. Siswa dan guru juga membutuhkan audio sebagai 
Fajar Arum Sari, dkk/ Piwulang 8 (1) (2020)

konfirmasi dengan alasan agar siswa mengetahui cara membaca teks berhuruf Jawa yang benar. Selain audio sebagai konfirmasi, dibutuhkan adanya backsound pada tampilan menu awal dengan alasan agar siswa tertarik terhadap multimedia interaktif. Oleh karena itu, multimedia interaktif pembelajaran membaca teks berhuruf Jawa menggunakan jenis huruf Tuladha Jejeg dan disertai adanya audio sebagai konfirmasi serta backsound pada tampilan menu awal.

Guru bahasa Jawa juga membutuhkan adanya materi aksara Jawa pada multimedia interaktif dengan alasan agar siswa dapat melatih keterampilan membaca teks berhuruf Jawa secara bertahap. Selain materi, guru juga membutuhkan adanya evaluasi agar mengetahui perkembangan keterampilan membaca nyaring siswa. Oleh karena itu, pada multimedia interaktif pembelajaran membaca teks berhuruf Jawa memuat teks mulai dari suku kata, kata, hingga paragraf sesuai dengan kompetensi dasar yang ada.

\section{Prototipe Multimedia Interaktif Pembelajaran}

\section{Membaca Teks Berhuruf Jawa}

Tampilan multimedia interaktif membaca teks berhuruf Jawa meliputi 1) tampilan awal dan 2)tampilan "Gladhen" yang didalamnya memuat 3 tahap untuk melatih keterampilan membaca teks berhuruf Jawa yaitu "Tembung", "Ukara", dan "Cariyos".

\section{Tampilan Menu Awal}

Halaman yang muncul ketika media dibuka yaitu menu awal dengan judul "Sinau Maca Aksara Jawa" yang didalamnya berisi menu Profil, Panduan, dan "Gladhen”. Menu awal ini disertai dengan backsound dan icon anak laki-laki yang menggunakan pakaian adat Jawa. Berikut merupakan tampilan menu awal pada multimedia interaktif membaca teks berhuruf Jawa.

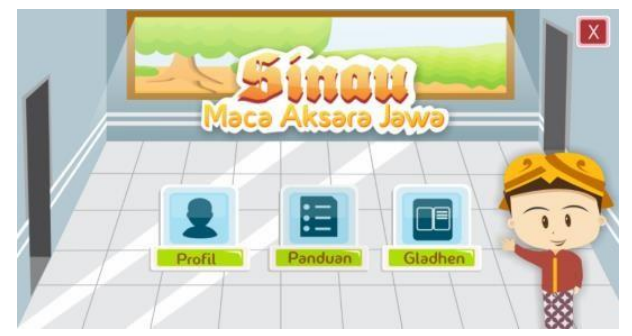

Gambar 1. Tampilan menu awal multimedia interaktif membaca teks berhuruf Jawa

\section{Tampilan Menu "Gladhen"}

Halaman menu "Gladhen" berisi menu "Tembung", "Ukara", dan "Cariyos". Pada menu "Gladhen" juga disertai dengan backsound dan icon gambar berupa anak laki-laki yang memakai pakaian adat Jawa. Berikut merupakan tampilan menu "Gladhen" pada multimedia interaktif membaca teks berhuruf Jawa.

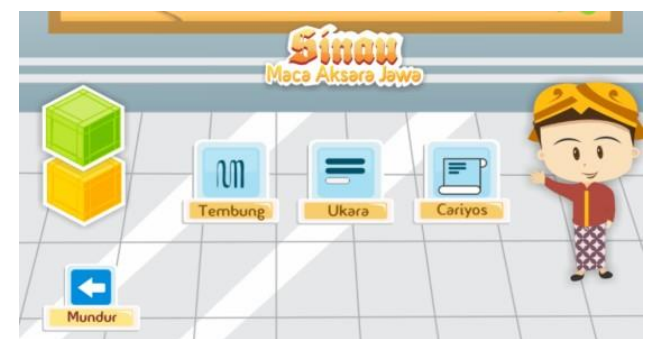

Gambar 2. Tampilan menu gladhen pada multimedia interaktif membaca teks berhuruf Jawa

\section{Tampilan Menu "Tembung"}

Halaman menu "Tembung berisi 20 kata berhuruf Jawa. Menurut Chaer (1994: 162), kata adalah satuan bahasa yang memiliki satu pengertian; atau kata adalah deretan huruf yang diapit oleh dua buah spasi, dan mempunyai satu arti. Materi 
Fajar Arum Sari, dkk/ Piwulang 8 (1) (2020)

yang terdapat pada menu "Tembung" yaitu kata berhuruf nglegena yang memuat sandhangan. Sandhangan tersebut seperti cakra dalam kata

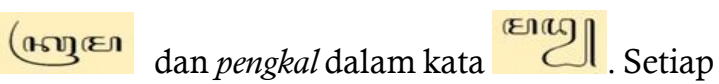
kata terdapat audio sebagai konfirmasi cara membaca yang benar. Siswa yang telah selesai membaca dapat mengkonfirmasi apakah yang dibaca sudah sesuai dengan audio sebagai konfirmasi. Berikut merupakan tampilan menu "Tembung" pada media ini.

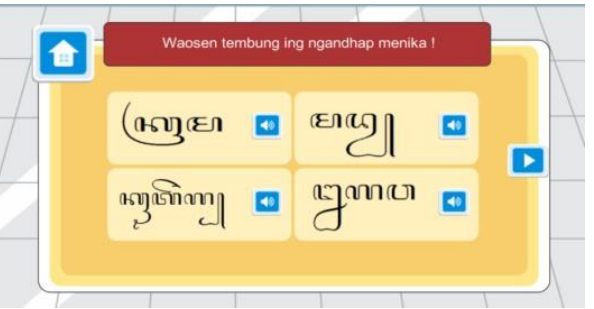

Gambar 3. Tampilan menu tembung pada multimedia interaktif membaca teks berhuruf Jawa

\section{Tampilan Menu "Ukara"}

Halaman menu "Ukara" berisi 20 kalimat berhurf Jawa. Menurut Chaer (1994: 240), kalimat adalah satuan sintaksis yang disusun dari konstituen dasar, yang biasanya berupa klausa, dilengkapi dengan konjungsi bila diperlukan, dan disertai dengan intonasi final. Kalimat yang digunakan pada multimedia interaktif adalah kalimat tunggal. Teori ini mengacu pada pemaparan Chaer (1994: 243) yang mengatakan bahwa jika klausa pada sebuah kalimat hanya satu, maka kalimat tersebut disebut kalimat tunggal.

Materi yang terdapat pada menu "Ukara" yaitu kalimat berhuruf nglegena yang memuat sandhangan dan pasangan berjumlah 20 teks serta dilengkapi dengan tanda baca. Pasangan yang disajikan seperti pasangan na dalam kalimat

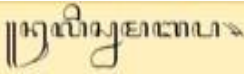

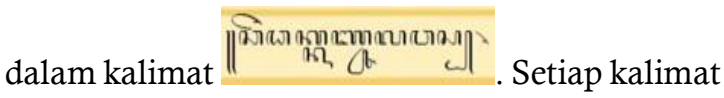
terdapat audio sebagai konfirmasi cara membaca yang benar. Siswa yang telah selesai membaca dapat mengkonfirmasi apakah yang dibaca sudah sesuai dengan audio sebagai konfirmasi. Berikut merupakan tampilan menu "Ukara" pada media ini.

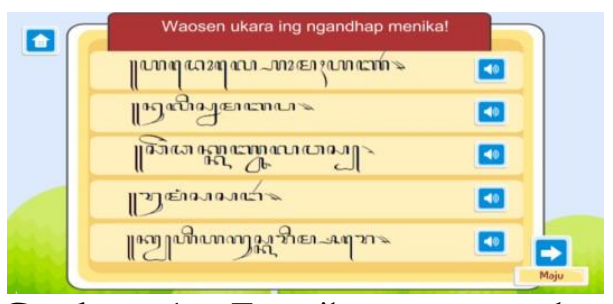

Gambar 4. Tampilan menu ukara pada multimedia interaktif membaca teks berhuruf Jawa

\section{Tampilan Menu "Cariyos"}

Halaman menu "Cariyos" berisi 14 kalimat berhuruf Jawa yang disertai dengan ilustrasi. Setiap kalimat saling berkaitan antara satu dengan yang lain, sehingga apabila dirangkai akan menjadi sebuah cerita yang utuh. Jenis teks yang digunakan pada multimedia interaktif ini yaitu teks narasi. Menurut Keraf (dalam Priyantono dan Sawukir, 2014: 118), narasi merupakan wujud karangan yang menceritakan asal mula kejadian hingga runtut. Teks narasi pada multimedia interaktif ini adalah teks cerita rakyat yang menceritakan asal mula kejadian Rawa Pening.

Pada menu ini juga terdapat audio sebagai konfirmasi cara membaca yang benar. Siswa yang telah selesai membaca teks juga dapat mengkonfirmasi apakah yang dibaca sudah 
Fajar Arum Sari, dkk/ Piwulang 8 (1) (2020)

sesuai dengan audio sebagai konfirmasi. Berikut merupakan tampilan menu "Cariyos" pada media ini.

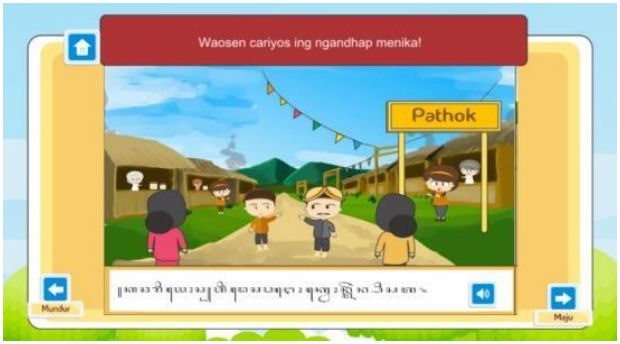

Gambar 5. Tampilan menu cariyos pada multimedia interaktif membaca teks berhuruf Jawa

\section{Validasi Desain Produk}

Uji validasi dilakukan oleh ahli materi, ahli media, dan guru sebagai pengguna. Berdasarkan penilaian dari ahli dan guru sebagai pengguna, multimedia interaktif pembelajaran membaca teks berhuruf Jawa dinilai sudah baik dengan memperoleh nilai rata-rata 3,3 yang berarti baik. Baik dari segi materi, ilustrasi, kejelasan pengisi suara, maupun desain media dinilai sudah baik. Akan tetapi, terdapat beberapa saran dan perbaikan terhadap aspek penulisan, kesesuain audio sebagai konfirmasi dan ukuran huruf yang masih mendapat nilai 2 atau cukup.

Kesalahan penulisan tersebut

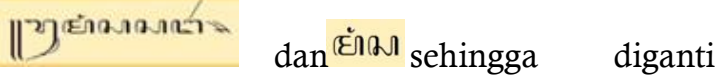

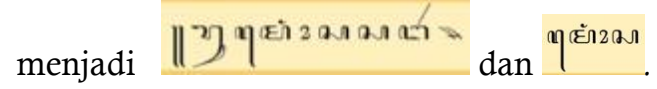

Pada aspek ukuran huruf dinilai terlalu kecil, terlebih untuk teks berhuruf Jawa yang dianggap rumit, sehingga hanya mendapat nilai 2 yang berarti cukup. Pakar ahli menyarankan agar teks berhuruf Jawa diperbesar dan tata letak gambar diperkecil. Hal lain yang dianggap kurang yaitu ketepatan pengisi suara yang berbeda dengan teks yang disajikan.

\section{Revisi Desain Media Interaktif}

Berdasarkan uji validasi desain produk, didapatkan hasil penilaian dan masukan sebagai dasar dalam melakukan perbaikan terhadap multimedia interaktif pembelajaran membaca teks berhuruf Jawa. Berikut merupakan hasil perbaikan desain produk multimedia interaktif pembelajaran membaca teks berhuruf Jawa.

\section{Ukuran Huruf Pada Menu "Cariyos"}

Berdasarkan validasi ahli oleh pakar media, ukuran huruf pada menu "Cariyos" dinilai masih terlalu kecil, terlebih untuk teks berhuruf Jawa yang dianggap rumit. Berikut merupakan tampilan pada menu "Cariyos" sebelum diperbaiki.

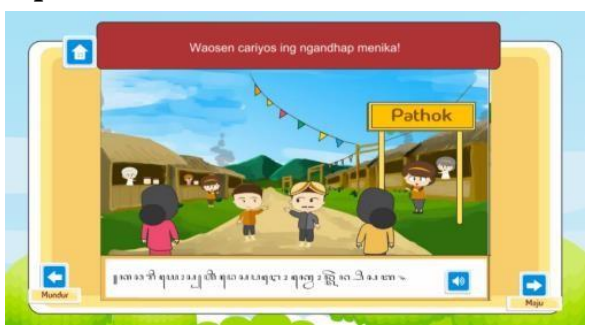

Gambar 6. Tampilan menu cariyos sebelum diperbaiki

Berdasarkan penilaian tersebut, perlu dilakukan perbaikan agar teks dapat terlihat lebih jelas bagi siswa, terlebih apabila multimedia interaktif ditayangkan menggunakan LCD. Berikut merupakan hasil perbaikan pada tampilan "Cariyos" setelah diperbaiki dengan memperbesar ukuran huruf dan memperkecil gambar. 
Fajar Arum Sari, dkk/ Piwulang 8 (1) (2020)

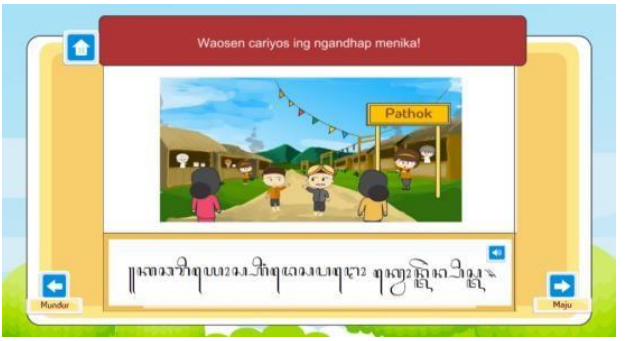

Gambar 7. Tampilan menu cariyos setelah diperbaiki

\section{Penulisan Kalimat Pada Menu "Ukara"}

Berdasarkan validasi ahli oleh pakar materi dan guru sebagai pengguna, diperoleh hasil bahwa terdapat kesalahan penulisan pada kalimat

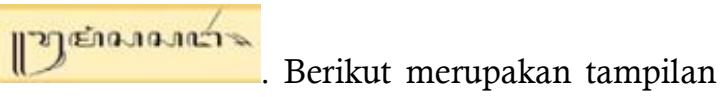
penulisan kalimat sebelum diperbaiki.

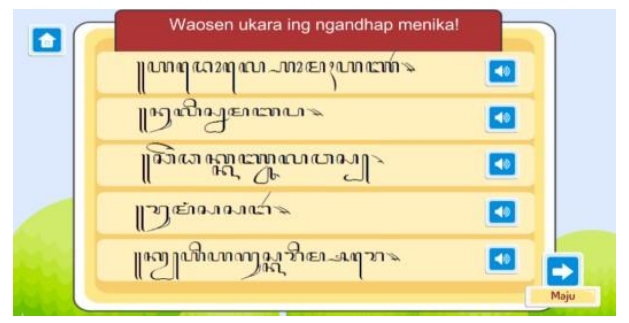

Gambar 8. Tampilan menu ukara sebelum diperbaiki

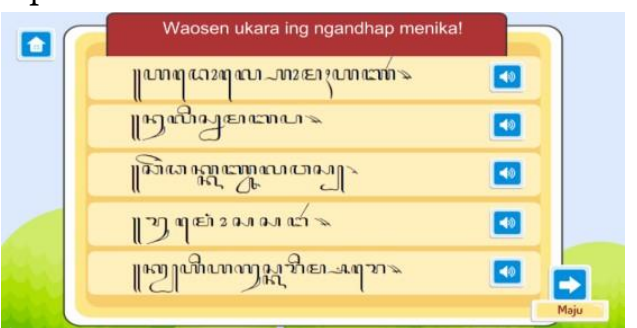

Gambar 9. Tampilan menu ukara sesudah diperbaiki

Berdasarkan penilaian oleh pakar materi dan guru sebagai pengguna, diperoleh saran dan perbaikan pada penulisan kalimat berhuruf Jawa

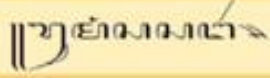

agar diganti menjadi

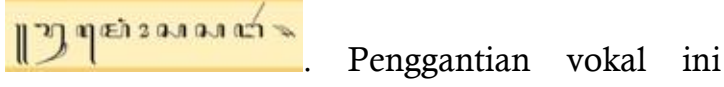
bertujuan agar lebih sesuai dengan pelafalan pada kata tersebut. Berikut merupakan hasil perbaikan pada penulisan kalimat.

\section{SIMPULAN}

Berdasarkan hasil penelitian pengembangan multimedia interaktif pembelajaran membaca teks berhuruf Jawa, diperoleh simpulan sebagai berikut.

1) Siswa membutuhkan media pembelajaran membaca teks berhuruf Jawa yang menarik, atraktif, dan interaktif, sehingga lebih menarik minat siswa dalam membaca teks berhuruf Jawa dan memudahkan siswa dalam belajar secara mandiri.

2) Prototipe media pembelajaran membaca teks berhuruf Jawa yang dihasilkan berupa multimedia interaktif yang didalamnya menyajikan teks berhuruf Jawa mulai dari tingkatan kata, kalimat, hingga cerita. Setiap teks dilengkapi dengan audio sebagai konfirmasi.

3) Berdasarkan hasil validasi serta dilakukannya perbaikan sesuai saran ahli, prototipe multimedia interaktif dinyatakan layak digunakan untuk pembelajaran membaca teks berhuruf Jawa di Kecamatan Ungaran Timur.

\section{DAFTAR PUSTAKA}

Arda dkk. 2015. "Pengembangan Media Pembelajaran Interaktif Berbasis Komputer untuk Siswa SMP Kelas VIII". E-Jurnal Mitra Sains. Januari 2015. 
Fajar Arum Sari, dkk/ Piwulang 8 (1) (2020)

Volume 3 Nomor 1. Palu: Universitas Tadulako. Diunduh tanggal 9 Agustus 2018, (jurnal.untad.ac.id).

Arsyad, Azhar. 2008. Media Pembelajaran. Jakarta: PT RajaGrafindo Persada.

Chaer, Abdul. 1994. Linguistik Umum. Jakarta: PT Rineka Cipta.

Mulyana. 2008. Pembelajaran Bahasa dan Sastra Daerah dalam Kerangka Budaya. Yogyakarta: Tiara Wacana.

Munir. 2013. Multimedia Konsep \& Aplikasi dalam Pendidikan. Bandung: Alfabeta.

Priyantono dan Sawukir. 2014. Marsudi: Basa lan Sastra Jawa. Jakarta: Erlangga.

Riyanto, Widodo Dwi dan Gunarhadi. 2017. "The Effectiveness of Interactive Multimedia in Mathematic Learning. (Utilizing Power Points for Students with Learning Disability)". International Journal of Pedagogy and Teacher.

Education (IJPTE). April 2017. Vol.1 Issue 1. Indonesia: Universitas Sebelas Maret. Diunduh 2 Agustus 2018, (https://jurnal.uns.ac.id/ijpte/arti cle/view/8400).

Sadiman, Arief S dkk. 2002. Media Pendidikan: Pengertian, Pengembangan dan Pemanfaatannya. Jakarta: PT RajaGrafindo Persada.

Sugiyono. 2010. Metode Penelitian Pendidikan. Bandung: Alfabeta.

Sukmadinata, Nana Syaodih. 2013. Metode Penelitian Pendidikan. Bandung: Remaja Rosdakarya. 